\title{
Editorial
}

\section{What is the state of the Antarctic environment?}

$\mathrm{T}$ he public is worried and so governments - at least the democratic ones - should also be worried. The global environment is changing and the consequences are still not understood. How much is natural and how much anthropogenic? In many cases the changes appear to be for the worse. Scientific opinion, as evidenced through the reports of the Intergovernmental Panel on Climate Change, is gloomy. By most estimates the rate of change will continue to increase and, if we cannot halt or slow the driving processes major modifications in where and how we live will be essential for survival. How do we know this and what should be done about it?

The harbingers of change have been obvious in some areas of the world for years. Increasing desertification, increasing salinisation of agricultural soils, increasing toxic chemicals in the food chains, increasing destruction of natural habitats all as a consequence of increasing populations and exploitation. The United Nations Environment Program was established specifically to address these problems and search for potential solutions. Many governments have become sufficiently alarmed by the trends in pollution, loss of productivity, destruction of habitats, increase in disease etc at the national, regional or global level that they have been embarking on baseline assessments - called state of the environment reporting - and the inauguration of monitoring programmes. UNEP is coordinating all these activities by many scientists worldwide to produce a state of the global environment report.

In some countries, and even regions, this has been going on for some time and already there are enough data to suggest what policies are needed to attempt to redress the balance. The European Environment Agency, for example, has provided clear indications at a regional level not only of continuing decline in the quality of life but also of the failure of new policies to arrest it. The same situation is clear in global data for fisheries, in the extent of tropical rain forests etc. The scientists can only provide the evidence and suggest probable cause. It is up to the politicians to provide the policies and the action - and commitment - to redress the balance. But without the relevant data how can anyone decide what to do?

For many years we have been telling the world that the Antarctic provides a unique and integrated baseline for measuring particular features of global change against which localised trends elsewhere can be compared. Where then is the political will to provide the state of the environment report for Antarctica that others can use as a standard? Why is it that this international area for peace and science is so far behind the rest of the world in drawing together the available data into a coherent report for the global public?

SCAR is at present conducting a primary scoping study on the extent of data available for preparing such a report. The results will be presented to the next Antarctic Treaty Consultative Meeting. What then will be the outcome? Is the Antarctic to be the only area of the world that does not contribute to the UNEP global report? New Zealand, which has already prepared reports on the state of their national environment, has undertaken to prepare a regional study of the state of the environment in the Ross Sea which will also be available to the next ATCM. One can only hope that these two documents together will convince the politicians that there is a case for funding the report for Antarctica and that the need for such a report is urgent.

D.W.H. WALTON 